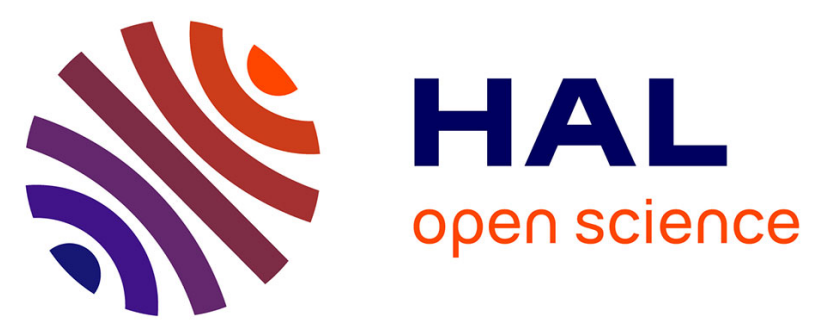

\title{
Adaptive Coordination-Driven Supramolecular Syntheses toward New Polymetallic Cu(I) Luminescent Assemblies
}

Sloane Evariste, Ali Moustafa Khalil, Mehdi Elsayed Moussa, Alan Kwun-Wa Chan, Eugene Yau-Hin Hong, Hok-Lai Wong, Boris Le Guennic, Guillaume Calvez, Karine Costuas, Vivian Wing-Wah Yam, et al.

\section{To cite this version:}

Sloane Evariste, Ali Moustafa Khalil, Mehdi Elsayed Moussa, Alan Kwun-Wa Chan, Eugene Yau-Hin Hong, et al.. Adaptive Coordination-Driven Supramolecular Syntheses toward New Polymetallic $\mathrm{Cu}(\mathrm{I})$ Luminescent Assemblies. Journal of the American Chemical Society, 2018, 140 (39), pp.12521-12526. 10.1021/jacs.8b06901 . hal-01862466

\section{HAL Id: hal-01862466 https://hal-univ-rennes1.archives-ouvertes.fr/hal-01862466}

Submitted on 18 Sep 2018

HAL is a multi-disciplinary open access archive for the deposit and dissemination of scientific research documents, whether they are published or not. The documents may come from teaching and research institutions in France or abroad, or from public or private research centers.
L'archive ouverte pluridisciplinaire HAL, est destinée au dépôt et à la diffusion de documents scientifiques de niveau recherche, publiés ou non, émanant des établissements d'enseignement et de recherche français ou étrangers, des laboratoires publics ou privés. 


\title{
Adaptive coordination-driven supramolecular syntheses toward new polymetallic $\mathrm{Cu}(\mathrm{I})$ luminescent assemblies.
}

\author{
Sloane Evariste, ${ }^{\dagger}$ Ali Moustafa Khalil, ${ }^{\dagger}$ Mehdi Elsayed Moussa, ${ }^{\dagger}{ }^{\dagger}$ Alan Kwun-Wa Chan, ${ }^{\ddagger}$ Eugene \\ Yau-Hin Hong, ${ }^{\ddagger}$ Hok-Lai Wong, ${ }^{\ddagger}$ Boris Le Guennic, ${ }^{\dagger}$ Guillaume Calvez, ${ }^{\dagger}$ Karine Costuas, ${ }^{*}{ }^{\dagger}$ Vivian \\ Wing-Wah Yam, ${ }^{* \ddagger}$ Christophe Lescop*' \\ ${ }^{\dagger}$ Univ. Rennes, INSA Rennes, CNRS, ISCR - UMR6226, F-35000 Rennes, France \\ ${ }^{\ddagger}$ Institute of Molecular Functional Materials [Areas of Excellence Scheme, University Grants Committee (Hong Kong)] and \\ Department of Chemistry, The University of Hong Kong, Pokfulam Road, Hong Kong, P.R. China.
}

\begin{abstract}
A TADF tetrametallic Cu(I) metallacycle A behaves as a conformationally adaptive pre-organized precursor to afford, through straightforward and rational coordination-driven supramolecular processes, a variety of room-temperature solidstate luminescent polymetallic assemblies. Reacting various cyano-based building blocks with A, a homometallic Cu(I) 1D-helical coordination polymer $\mathbf{C}$ and $\mathrm{Cu}_{8} \mathrm{M}$ discrete circular hetero-bimetallic assemblies $\mathbf{D}_{\mathbf{M}}(\mathbf{M}=\mathrm{Ni}, \mathrm{Pd}$, Pt) are obtained. Their luminescence behaviours are studied, revealing notably the crucial impact of the spin-orbit coupling offered by the central $\mathrm{M}$ metal center on the photophysical properties of the hetero-bimetallic $\mathbf{D}_{\mathbf{M}}$ derivatives.
\end{abstract}

\section{INTRODUCTION}

Coordination-driven supramolecular synthesis (CDS) has emerged in the last decade as one of the most powerful modern synthetic strategies for providing an impressive number of increasingly complex supramolecular assemblies. ${ }^{1}$ CDS uses the robust, reversible and directional metal-ligand coordinative bond to selectively build high-order functional metallosupramolecular architectures via the self-assembly of discrete individual components (metal centers and multitopic linkers) having pre-defined geometries and connectivities. Recently, thermally activated delayed fluorescence (TADF) $\mathrm{Cu}(\mathrm{I})$ coordination complexes have witnessed impressive developments ${ }^{2}$ due to their exalted photophysical performances, that can now compete with those of phosphorescent derivatives based on expensive heavy metal complexes. ${ }^{3}$ Nevertheless, no studies have focused up to now on the use of such cheap TADF $\mathrm{Cu}(\mathrm{I})$ complexes as pre-organized precursors for the general CDS of emissive coordination-driven supramolecular assemblies. This might be due to the fact that $\mathrm{Cu}(\mathrm{I})$ complexes are expected to present labile and non-directional coordination spheres which is a priori biased misperception to allow selective CDS toward discrete well-defined metallo-supramolecular architectures. Herein we report for the first time the selective one-step CDS of a series of multimetallic luminescent $\mathrm{Cu}(\mathrm{I})$ supramolecular assemblies using the $\mathrm{Cu}(\mathrm{I})$ derivative $\mathbf{A}^{4}$ (Figure 1 ) as preorganized adaptive supramolecular precursor. We also show that these new derivatives present a variety of emissive behaviours, opening up new perspectives in luminophor design and in the manifold fields of applications that these derivatives can address (lighting and visual displays, telecommunication, sensors etc.).

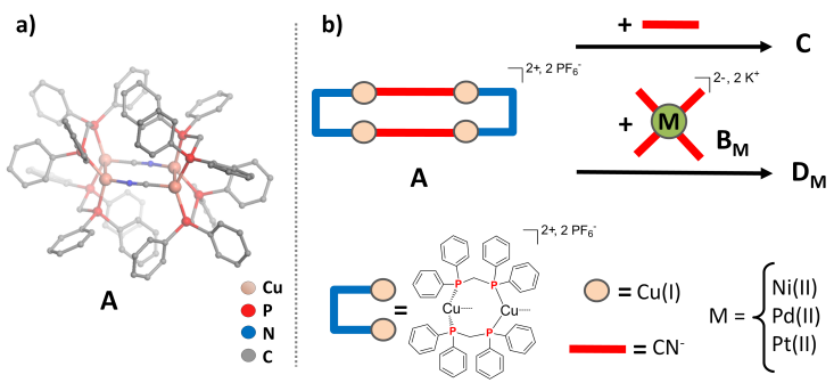

Figure 1. (a) Molecular structure of the dicationic precursor A; (b) Syntheses of the derivatives $\mathbf{C}$ and $\mathbf{D}_{\mathbf{M}}$.

\section{RESULTS AND DISCUSSION}

Due to specific molecular design, some Cu(I) bimetallic precursors bearing short intermetallic distances and conformationally stable coordination directions have been identified as versatile pre-organized precursors. ${ }^{5}$ Very specific CDS toward compact supramolecular metallacycles could thus be conducted, including the one-step quantitative preparation ${ }^{6}$ of the blue-luminophor consisting of tetrametallic $\mathrm{Cu}(\mathrm{I})$ compact metallacycle A (Figure 1a). ${ }^{4} \mathbf{A}$ is a result of the selective selfassociation of two $\left[\mathrm{Cu}_{2}\left(\mu_{2}-\mathrm{dppm}_{2}\right)\right]$ fragments with two cyano ditopic linkers and undergoes very efficient TADF processes in the solid state. ${ }^{4}$ In $\mathbf{A}$, the four $\mathrm{Cu}(\mathrm{I})$ metal centers possess trigonal planar coordination spheres that could allow additional coordination of donor ligands to gain access to new supramolecular assemblies. In order to probe this assumption, A was reacted (Figure $1 \mathrm{~b}$ ) with $\mathrm{KCN}$ and the tetracyanometallated $\mathrm{K}_{2}\left[\mathrm{M}(\mathrm{CN})_{4}\right]$ metallo-ligands $\mathbf{B}_{\mathbf{M}}\left(\mathbf{B}_{\mathrm{Ni}}, \mathbf{M}=\mathrm{Ni} ; \mathbf{B}_{\mathbf{P d}}, \mathbf{M}=\mathrm{Pd}\right.$; $\mathbf{B}_{\mathbf{P t}}, \mathbf{M}=\mathrm{Pt}$ ), playing the role of, respectively, potential linear and square planar polytopic 
a)

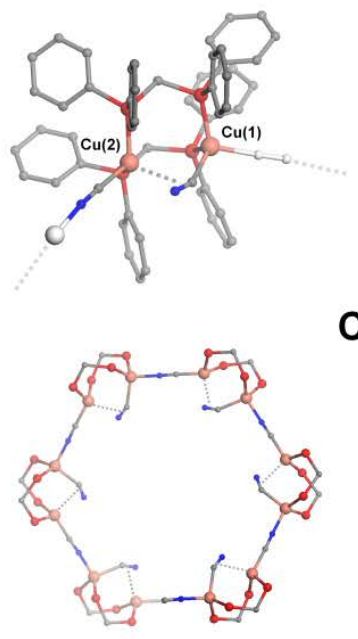

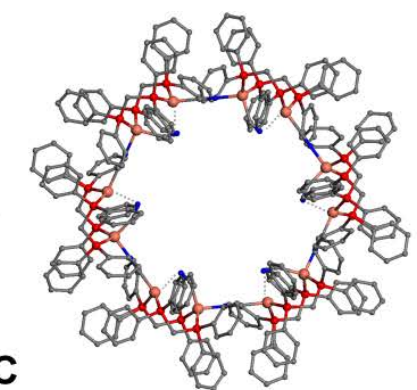

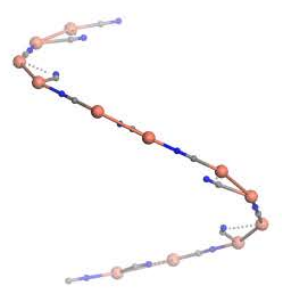

b)

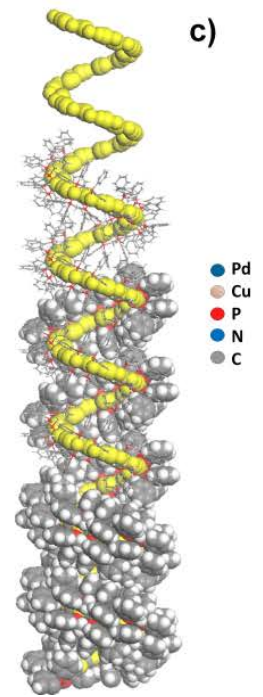

c)
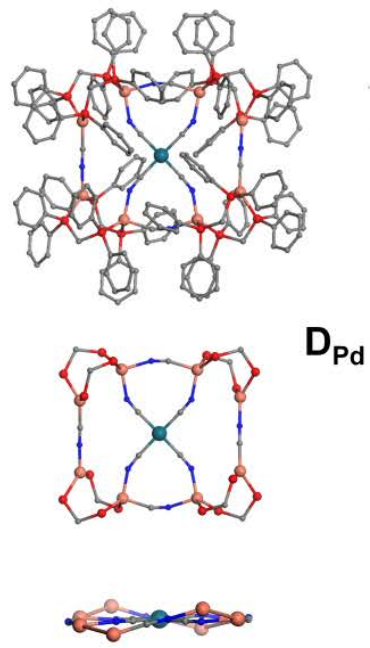

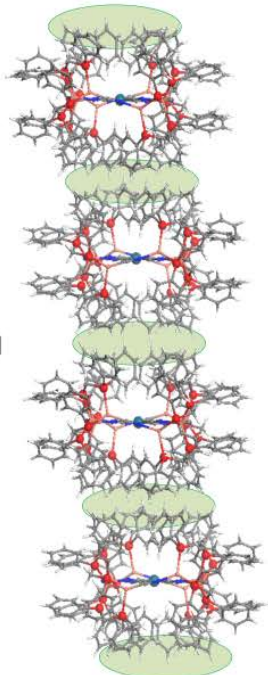

Figure 2. a) Molecular X-ray structure of the bimetallic repetition unit of $\mathbf{C}$ (left top), view of the 1D-helicoidal coordination polymer $\mathbf{C}$ along the c axis showing six repetition units' pitch (right top), simplified 'top' and side views of the showing six repetition units' pitch of $\mathbf{C}$ (bottom); b) view perpendicular to the c axis of the $1 \mathrm{D}$ helicoidal polymer $\mathbf{C}$ with a gradual CPK style to stick and ball-style to a removal of the dppm ligands, the $(\mathrm{CuCN})_{\mathrm{n}}$ helicoidal chain located in the wall of the 1D-channels formed being shown in CPK style in yellow; c) Molecular X-ray structure, simplified 'top' and side views of the derivative $\mathbf{D}_{\mathbf{P d}}$ and columnar solid state stacking of the derivative $\mathbf{D}_{\mathbf{P d}}$, the green ellipses represent the intermolecular contact areas involving $\pi$ - $\mathrm{CH}$ interactions (Counteranions, $\mathrm{H}$ atoms and solvent molecules have been omitted for clarity; location of the $\mathrm{C}$ and $\mathrm{N}$ atoms of the cyano ligands has been chosen arbitrarily in the X-ray structure views except for the $\mathrm{M}(\mathrm{CN})_{4}$ fragments).

inorganic linkers. As the colorless $\mathrm{CH}_{2} \mathrm{Cl}_{2}$ solutions of the metallacycle $\mathbf{A}$ were mixed with methanol solutions of $\mathrm{KCN}$ and of precursors $\mathbf{B}_{\mathbf{M}}$, neither color changes nor precipitates were observed. Yet, upon UV light excitation at $365 \mathrm{~nm}$, an instantaneous change of the color of the light emitted by the solution occurred. For the reactions with $\mathrm{KCN}, \mathbf{B}_{\mathrm{Ni}}$ and $\mathbf{B}_{\mathbf{P d}}$, the eye-perceived emitted color changed from blue (typical of $\mathrm{CH}_{2} \mathrm{Cl}_{2}$ solutions of the metallacycle A) to orange, and to yellow for the reaction conducted with $\mathbf{B}_{\mathbf{P t}}$. Accordingly, the emission spectra recorded for these crude solutions (Figure S19) revealed a red-shift of the large emission band observed for A, suggesting that the reaction occurs immediately between $\mathbf{A}$ and $\mathrm{KCN}$ or $\mathbf{B}_{\mathbf{M}}$ to afford new derivatives whose electronic structures are altered compared to that of $\mathbf{A}$. After crystallization, these crude solutions afforded respectively the new derivatives $\mathbf{C}$ and $\mathbf{D}_{\mathbf{M}}\left(\mathbf{D}_{\mathrm{Ni}}, \mathbf{M}=\mathrm{Ni} ; \mathbf{D}_{\mathbf{P d}}, \mathbf{M}=\mathrm{Pd} ; \mathbf{D}_{\mathbf{P t}}, \mathbf{M}\right.$ $=\mathrm{Pt}$ ) as air-stable colorless polycrystalline derivatives in good overall yields (Figure 1b). ${ }^{6}$ These derivatives are moderately soluble in chlorinated solvents. Their ${ }^{31} \mathrm{P}\left\{{ }^{1} \mathrm{H}\right\}$ NMR spectra ${ }^{6}$ recorded in $\mathrm{CD}_{2} \mathrm{Cl}_{2}$ reveal one broad singlet at $-14.8 \mathrm{ppm}$ for $\mathbf{C}$ and two broad singlets for $\mathbf{D}_{\mathbf{M}}$ complexes $\left(\mathbf{D}_{\mathbf{N i}}, \delta=-17.0\right.$ and $-19.1 \mathrm{ppm} ; \mathbf{D}_{\mathbf{P d}}, \delta=-16.3$ and $-18.7 \mathrm{ppm} ; \mathbf{D}_{\mathbf{P t}}, \delta=-16.3$ and $-18.6 \mathrm{ppm}$ ) that are shifted to low frequencies compared to the two broad singlets observed for $\mathbf{A}(\delta=-8.5 \mathrm{ppm}$ and $-10.5 \mathrm{ppm}) .{ }^{4}$ Their ${ }^{1} \mathrm{H}$ NMR spectra presented similar patterns in which the ${ }^{1} \mathrm{H}$ NMR resonances of the dppm methylene protons are split into two groups of broad signals indicating their non-equivalence. These data suggest that the $1 \kappa \mathrm{P}: 2 \kappa \mathrm{P}-$ coordination of the dppm ligands observed in the precursor $\mathbf{A}$ is retained in these new derivatives, in which the gross molecular structure of the $\mathrm{Cu}_{2}\left(\mu_{2} \text {-dppm }\right)_{2}$ fragment serves as the building unit. In addition, solid-state infrared spectra show two different $v(\mathrm{C} \equiv \mathrm{N})$ stretches (2071 and $2120 \mathrm{~cm}^{-1}$ ) for $\mathbf{C}$ (cf.
$v(\mathrm{C} \equiv \mathrm{N}): 2117 \mathrm{~cm}^{-1}$ for $\left.\mathbf{A}\right),{ }^{4}$ suggesting two different coordination modes for the cyano ligands, while for $\mathbf{D}_{\mathbf{M}}$ complexes it reveals $v(\mathrm{C} \equiv \mathrm{N})$ modes corresponding to $\mathrm{Cu}-\mathrm{CN}-\mathrm{Cu}\left(\mathbf{D}_{\mathrm{Ni}}, 2124\right.$ $\left.\mathrm{cm}^{-1} ; \mathbf{D}_{\mathbf{P d}}, 2121 \mathrm{~cm}^{-1} ; \mathbf{D}_{\mathbf{P t}}, 2121 \mathrm{~cm}^{-1}\right)$ and Cu-CN-M ( $\mathbf{D}_{\mathrm{Ni}}$, $2138 \mathrm{~cm}^{-1} ; \mathbf{D}_{\mathbf{P d}}, 2141 \mathrm{~cm}^{-1} ; \mathbf{D}_{\mathbf{P t}}, 2151 \mathrm{~cm}^{-1}$ ) fragments.

Finally, the molecular structures of derivatives $\mathbf{C}$ and $\mathbf{D}_{\mathbf{M}}$ complexes were established by X-ray diffraction studies ${ }^{6}$ performed at low temperature on single crystals obtained at room temperature (RT) from pentane diffusion into $\mathrm{CH}_{2} \mathrm{Cl}_{2}$ solutions of the respective complexes. The derivative $\mathbf{C}$ crystallizes as a neutral $1 \mathrm{D}$-coordination polymer (which is likely to dissociate in solution). The repeating unit is based on a $\mathrm{Cu}_{2}\left(\mu_{2^{-}}\right.$ $\mathrm{dppm})_{2}$ fragment, on which two different cyano ligands are coordinated to the metal centers (Figure 2a, left top). ${ }^{7}$ One of these cyano ligands acts as $\mu_{2}$-ditopic linker between two $\mathrm{Cu}(\mathrm{I})$ metal centers of two neighboring repeating units while the second cyano ligand bridges the two metal centers within each $\mathrm{Cu}_{2}\left(\mu_{2} \text {-dppm }\right)_{2}$ fragment in an unusual 'end-on/side-on' coordination mode. As a result, the $\mathrm{Cu}(1)$ metal center bears a distorted tetrahedral coordination sphere while the $\mathrm{Cu}(2)$ atom presents a distorted trigonal planar coordination sphere (the 'side-on' interaction is not taken into account in this description). In these dimers, the intermetallic distance $(\mathrm{d}(\mathrm{Cu}-\mathrm{Cu})=$ $3.48 \AA)$ is larger than in $\mathbf{A}(\mathrm{d}(\mathrm{Cu}-\mathrm{Cu})=2.87 \AA)$ and precludes cuprophilic interactions in $\mathbf{C}$. The $\mu_{2}$-cyano ligands present almost linear coordination angle on the metal centers (Cu-C-N $=177.8(6)^{\circ}$ and $\left.177.9(5)^{\circ}\right)$ while the bridging cyano ligands show a significantly more bent coordination to the $\mathrm{Cu}(\mathrm{I})$ ions $\left(\mathrm{Cu}-\mathrm{C}-\mathrm{N}=64(1)^{\circ}\right.$ and $\left.157(1)^{\circ}\right){ }^{7}$ Five highly disordered $\mathrm{CH}_{2} \mathrm{Cl}_{2}$ molecules complete the asymmetric unit. The solidstate infinite structure of $\mathbf{C}$ is formed by the connection of these bimetallic repeating units to afford a remarkable neutral $1 \mathrm{D}$-helicoidal coordination polymer whose pitch is based on 
the connection of six repeating units (Figure 2a). Finally, in the extended solid state, helices are oriented parallel to the $c$ axis affording a molecular solid in which infinite channels (with cross-sectional diameter: ca. $10 \AA$, filled by the $\mathrm{CH}_{2} \mathrm{Cl}_{2}$ molecules) having inner walls bearing $(\mathrm{CuCN})_{\mathrm{n}}$ helical wire are observed (Figure 2b). It is worth to note that since $\mathbf{C}$ crystallizes in a non-centrosymmetric space group, only one kind of helical structure (P or $\mathrm{M}$ ) is found in a single crystal. Nevertheless, the crystallization process being not enantioselective, single crystals bearing both right- and left- handed helices are collected.

Isostructural derivatives $\mathbf{D}_{\mathbf{M}}$ are discrete polymetallic assemblies. The asymmetric units contain one dicationic $\mathrm{Cu}_{8} \mathrm{M}_{1}(\mathrm{CN})_{8} \mathrm{dppm}_{8}$ discrete unit, two hexafluorophosphate counter-anions and ten disordered $\mathrm{CH}_{2} \mathrm{Cl}_{2}$ solvent molecules. These $\mathrm{Cu}_{8} \mathrm{M}_{1}(\mathrm{CN})_{8} \mathrm{dppm}_{8}$ complexes (Figure $2 \mathrm{~b}$ ) bear a central square-planar ' $\mathrm{M}(\mathrm{CN})_{4}$ ' unit surrounded by a ' $\mathrm{Cu}_{8}(\mathrm{CN})_{4}$ ' metallacycle which can be described as the connection of four $\mathrm{Cu}_{2}\left(\mu_{2} \text {-dppm }\right)_{2}$ fragments by four peripheral $\mu_{2}-\mathrm{CN}$ ligands. ${ }^{7}$ In each $\mathrm{Cu}_{2}\left(\mu_{2} \text {-dppm }\right)_{2}$ fragment, one of the metal centers has a distorted trigonal planar coordination sphere resulting from the coordination of two $1 \kappa \mathrm{P}: 2 \kappa \mathrm{P}$ dppm ligands and the peripheral cyano ligands. The second $\mathrm{Cu}(\mathrm{I})$ metal center presents a distorted tetrahedral coordination sphere due to an additional link with a central $\mu_{2}$-CN ligand, which connects the ' $\mathrm{Cu}_{8}(\mathrm{CN})_{4}{ }^{\prime}$ metallacycle to the central ' $\mathrm{MCN}_{4}$ ' fragment. Within the ${ }^{\prime} \mathrm{Cu}_{8}(\mathrm{CN})_{4}$ ' metallacycle, the distorted trigonal planar $\mathrm{Cu}(\mathrm{I})$ ions as well as the distorted tetrahedral $\mathrm{Cu}(\mathrm{I})$ ions are connected together two by two by a peripheral $\mu_{2}-\mathrm{CN}$ ligand (Figure 2c). The resulting ' $\mathrm{Cu}_{8} \mathrm{M}(\mathrm{CN})_{8}$ ' inorganic cores show almost planar gross rectangular shapes (Figure 2c; maximum deviation from the mean plane defined by the ' $\mathrm{Cu}_{8} \mathrm{M}(\mathrm{CN})_{8}$ ' fragment $\left.=0.531 \AA\left(\mathbf{D}_{\mathrm{Ni}}\right) ; 0.665 \AA\left(\mathbf{D}_{\mathbf{P d}}\right) ; 0.640 \AA\left(\mathbf{D}_{\mathbf{P t}}\right)\right)$ of similar size despite the different atomic radii of the central metal ions $\left(10.7 * 9.6 \AA^{2}\left(\mathbf{D}_{\mathrm{Ni}}\right) ; 10.6 * 9.7 \AA^{2}\left(\mathbf{D}_{\mathbf{P d}}\right) ; 10.6 * 9.6 \AA^{2}\left(\mathbf{D}_{\mathbf{P t}}\right)\right.$, Figure S18). Intermetallic $\mathrm{Cu}(\mathrm{I})$ distances in the $\mathrm{Cu}_{2}\left(\mu_{2}-\mathrm{dppm}\right)_{2}$ fragments are too large for cuprophilic interactions $(\mathrm{d}(\mathrm{Cu}-\mathrm{Cu})$ $=3.35-3.48 \AA\left(\mathbf{D}_{\mathrm{Ni}}\right) ; 3.36-3.46 \AA\left(\mathbf{D}_{\mathbf{P d}}\right) ; 3.36-3.44 \AA$ $\left.\left(\mathbf{D}_{\mathbf{P t}}\right)\right)$. The peripheral cyano ligands present slightly tilted coordination angle with the metal centers ( $\mathrm{Cu}-\mathrm{C}-\mathrm{N}=158.3^{\circ}$ $175.9^{\circ}$ ). The central cyano ligands are almost linear at the $\mathrm{M}$ metal centers $\left(\mathrm{M}-\mathrm{C}-\mathrm{N}=175.2^{\circ}-177.8^{\circ}\right)$ but present much more bent coordination angles on the $\mathrm{Cu}(\mathrm{I})$ ions $(\mathrm{Cu}-\mathrm{C}-\mathrm{N}=$ $\left.145.4^{\circ}-153.3^{\circ}\right)$. Finally, $\mathbf{D}_{\mathbf{M}}$ derivatives stack on the top of each other in the crystalline solid state along infinite columns (Figure 2c), presumably allowing the maximization of cumulative stabilizing $\mathrm{CH}-\pi$ interactions between most of the phenyl rings of the dppm ligands of neighboring assemblies.

At first glance, the discrepancy observed between the supramolecular structures characterized (1D-helicoidal coordination polymer $\mathbf{C}$ versus discrete polymetallic assemblies $\mathbf{D}_{\mathbf{M}}$ ) might seem inappropriate to consider $\mathbf{A}$ as a directional preorganized precursor in CDS. Nevertheless, it can be rationalized by considering that the derivative $\mathbf{A}$ is the result of the dimerization of reactive and adaptable " $\mathrm{Cu}_{2}\left(\mu_{2} \text {-dppm }\right)_{2} \mathrm{CN}$ " fragments A' bearing coordinatively highly unsaturated $\mathrm{Cu}(\mathrm{I})$ metal centers (Scheme 1). Indeed, in such an hypothesis, a reversible equilibrium is likely to occur in solution between $\mathbf{A}$ and $\mathbf{A}$ ' allowing reaction of the latter with additional free cyano ligands or $\mathrm{M}(\mathrm{CN})_{4}{ }^{2-}$ fragments (Scheme 1 ). In the first case, the cyano ligand can be considered as formally inserted within the metal centers of A' affording " $\mathrm{Cu}_{2}\left(\mu_{2}-\mathrm{dppm}\right)_{2} \mathrm{CN}$ ”
Scheme 1. Suggested mechanism of self-assembling for the syntheses of $C$ and $D_{M}$ from the precursor $A$.

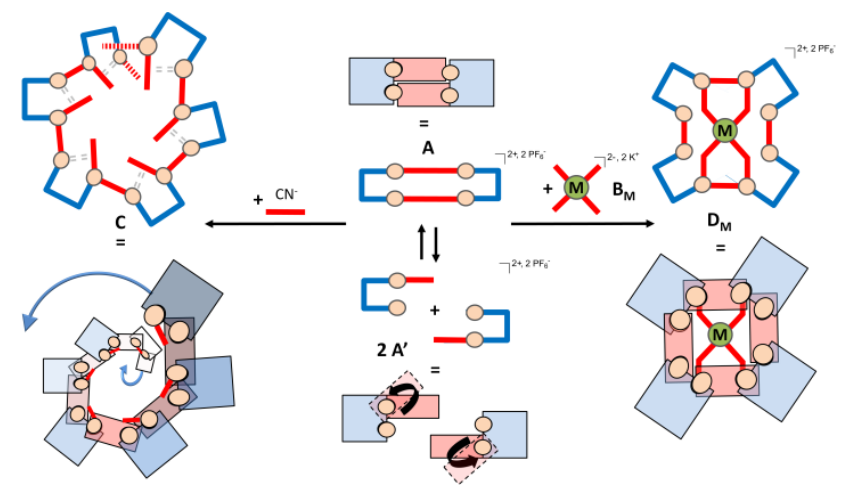

fragments that self-assemble in the 1D-helicoidal structure of C. In the second case, the square planar $\mathrm{M}(\mathrm{CN})_{4}{ }^{2-}$ building block acts as a template to connect four $\mathbf{A}^{\prime}$ units in the discrete assemblies $\mathbf{D}_{\mathbf{M}}$ (Scheme 1). Importantly, such self-assembly processes do not strictly follow the basic guiding rules of the CDS chemistry, since the pre-organized bimetallic building blocks do not present rigid geometric constraints that will impose the geometry of the supramolecular assemblies obtained. However, the lability of the cyano ligands and the conformational flexibility of the " $\mathrm{Cu}_{2}\left(\mu_{2} \text {-dppm }\right)_{2} \mathrm{CN}$ ” building block have allowed the selective and rational design of new supramolecular assemblies $\mathbf{C}$ and $\mathbf{D}_{\mathbf{M}}$ (Scheme 1) based on an adaptable pre-organized stable molecular clip.

Temperature-dependent X-ray crystal structure analyses ${ }^{6}$ were performed on single crystals of $\mathbf{C}, \mathbf{D}_{\mathbf{P d}}$ and $\mathbf{D}_{\mathbf{P t}}$ in order to get insights about the structural rigidity of these derivatives upon cooling from $250 \mathrm{~K}$ to $100 \mathrm{~K}$. Besides a moderate and progressive shrinkage of the unit cell volume upon cooling ( $\mathrm{ca}$. $3.0 \%$, $3.8 \%$ and $4.1 \%$ volume contraction for $\mathbf{C}, \mathbf{D}_{\mathbf{P d}}$ and $\mathbf{D}_{\mathbf{P t}}$ respectively), these measurements reveal a significant temperature-dependent molecular arrangement in $\mathbf{C}$ (Figure 3 and S13, Table S6) while the molecular geometry in $\mathbf{D}_{\mathbf{P d}}$ and $\mathbf{D}_{\mathbf{P t}}$ are mostly unchanged. ${ }^{8}$ Indeed, in $\mathbf{C}$, the intermetallic distances within the $\mathrm{Cu}_{2}\left(\mu_{2} \text {-dppm }\right)_{2}$ fragment are decreased upon cooling (d(Cu-Cu), $3.55 \AA$ (250 K); $3.51 \AA$ (175 K); $3.48 \AA$ $(100 \mathrm{~K}))$. Concomitantly, within this fragment, the 'endon/side-on' coordinated cyano ligand is found to be
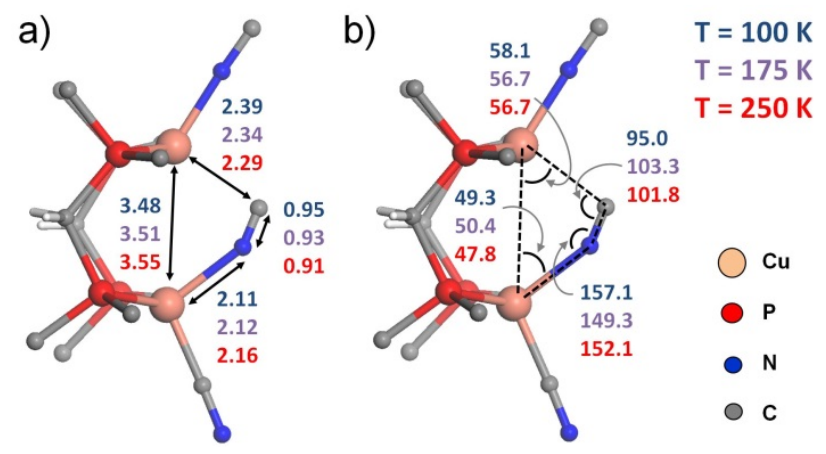

Figure 3. Temperature variation of a) selected lengths ( $\AA$ ) and b) angles $\left(^{\circ}\right.$ ) in the repetition unit of the X-ray structure of $\mathbf{C}$ (phenyl rings have been omitted for clarity). 
significantly labile presenting shorter Cu-terminal N/C atom distances at low temperature and a tendency to partially decoordinate and switch from the 'end-on/side-on' coordination mode to a lateral $\mu_{2}$-coordination mode at high temperature.

Derivatives $\mathbf{C}$ and $\mathbf{D}_{\mathbf{M}}$ display solid-state luminescence properties that are markedly different from those of the precursor $\mathbf{A}{ }^{6}$ Crystalline samples of the neutral helix $\mathbf{C}$ display at $298 \mathrm{~K}$ an eye-perceived yellow luminescence under excitation at 320 $\mathrm{nm}$ characterized by a broad and featureless band in the emission spectrum with a maximum at $538 \mathrm{~nm}$ (Figure 4a) and an emission quantum yield (EQY) of $20 \%$. The emission band at $538 \mathrm{~nm}$ is typical of metal-perturbed dppm ligand-centered phosphorescence. ${ }^{9}$ Upon cooling from $290 \mathrm{~K}$ to $90 \mathrm{~K}$ under excitation at $320 \mathrm{~nm},{ }^{6}$ a gradual drop of the emission band at $538 \mathrm{~nm}$, together with a growth of a higher-energy band to the blue, is observed (Figure 4a) affording at $77 \mathrm{~K}$ an emission maximum of $468 \mathrm{~nm}\left(\Delta \lambda_{\mathrm{em}}=0.344 \mathrm{eV}\left(2780 \mathrm{~cm}^{-1}\right)\right)$ associated with an intense solid-state visually-perceived blue luminescence. Such a shift of emission maxima to the blue upon decreasing temperature is suggestive of the lack of a TADF mechanism in $\mathbf{C}$. The higher-energy emission band is likely a result of an emission origin of metal-to-ligand charge transfer (MLCT) $\left[\mathrm{d} \sigma^{*}(\mathrm{Cu}) \rightarrow \pi^{*}(\mathrm{CN}) / \pi^{*}(\mathrm{dppm})\right]$ state with mixing of a copper-centered d-s/d-p excited state modified by the very weak $\mathrm{Cu}{ }^{\cdots} \mathrm{Cu}$ interaction. Emission bands of similar energy are also found in other related systems. ${ }^{10}$ Interestingly, a change is also observed upon variation of the excitation wavelength at $77 \mathrm{~K}$ (Figure 4b). The shift in emission maxima and the change in the relative ratio of the high-energy and lowenergy bands with excitation wavelength are typical of multiple emission arising from multiple species and site heterogeneity, typically found in polymeric species as is the case of the helicoidal polymeric nature of $\mathbf{C}$.

Considering complex $\mathbf{D}_{\mathrm{Ni}}$, only very weak emission is observed in the solid state, with a gradual red shift upon cooling from $400 \mathrm{~K}$ to $77 \mathrm{~K}$ (Figure S25). Its very weak luminescence and uncertainty in lifetime measurements have precluded its emission origin assignment. Conversely, in the solid state, the derivative $\mathbf{D}_{\mathbf{P d}}$ displays at $298 \mathrm{~K}$ a moderate turquoise luminescence upon excitation at $350 \mathrm{~nm}$ with emission maximum $\lambda_{\text {em }}$ at $500 \mathrm{~nm}$ (Figure 4c). This emission band is broad and featureless with an emissive lifetime $\tau$ of $12 \mu \mathrm{s}$ at $298 \mathrm{~K}$ and an EQY of $2 \%$. In addition, at $298 \mathrm{~K}, \mathbf{D}_{\mathbf{P t}}$ exhibits intense turquoise luminescence upon excitation at $350 \mathrm{~nm}$ characterized also by a broad and featureless emission band $\left(\lambda_{\text {em }}=510\right.$ $\mathrm{nm}, \tau=$ ca. $8 \mu \mathrm{s}, \mathrm{EQY}=18 \%$ ). Upon cooling in the solid state with excitation at $350 \mathrm{~nm}$, both emission spectra of derivatives $\mathbf{D}_{\mathbf{P d}}$ and $\mathbf{D}_{\mathbf{P t}}$ present gradual red-shifts associated with intense solid state green luminescence at low temperature (Figure 4c,d: for $\mathbf{D}_{\mathbf{P d}}$ from $\lambda_{\mathrm{em}}=493 \mathrm{~nm}$ at $430 \mathrm{~K}$ to $\lambda_{\mathrm{em}}=515 \mathrm{~nm}$ at $77 \mathrm{~K}\left(\Delta \lambda_{\mathrm{em}}=0.108 \mathrm{eV} / 870 \mathrm{~cm}^{-1}\right)$ and for $\mathbf{D}_{\mathbf{p t}}$ from $\lambda_{\mathrm{em}}=486$ $\mathrm{nm}$ at $400 \mathrm{~K}$ to $\lambda_{\text {em }}=510 \mathrm{~nm}$ at $77 \mathrm{~K} \mathrm{~nm}\left(\Delta \lambda_{\text {em }}=0.120 \mathrm{eV} /\right.$ $\left.968 \mathrm{~cm}^{-1}\right)$ ). It is worth to note that the energy shift in the $\mathbf{D}_{\mathbf{P d}}$ derivative is relatively small compared to the one observed for its $\mathbf{D}_{\mathbf{P t}}$ analog while the energy domain in which their thermochromic luminescence is observed is mostly the same (together with the thermochromic shift observed for the very weak emission spectrum of $\mathbf{D}_{\mathrm{Ni}}$, Figure S25). However, there are much significant changes in their respective emission decay lifetime $\tau$ upon cooling. Indeed, it varies from $c a .2 .7 \mu$ s at $400 \mathrm{~K}$ to $c a .222 \mu$ s at $80 \mathrm{~K}$ for derivative $\mathbf{D}_{\mathbf{P d}}$ while it varies
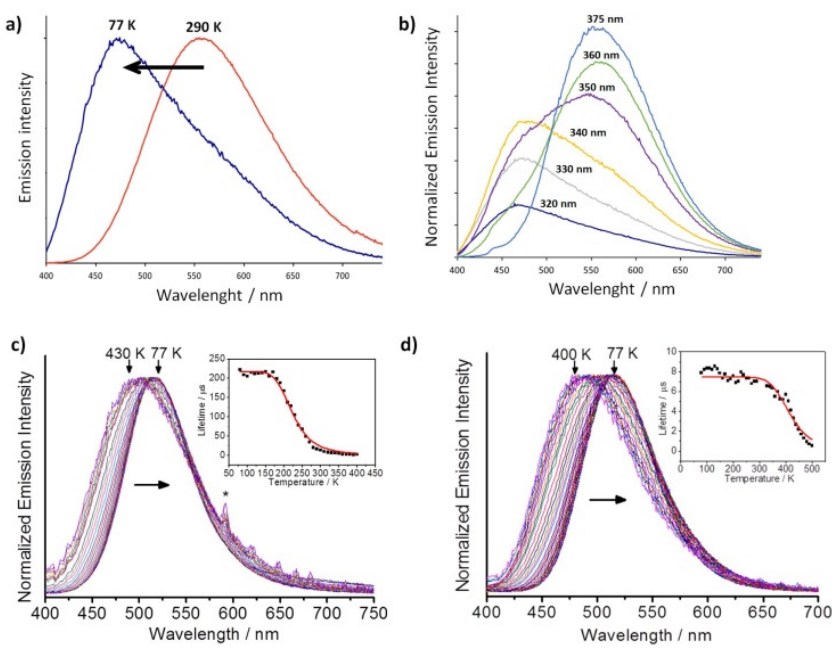

Figure 4. a) Normalized solid-state emission spectra of $\mathbf{C}$ at $77 \mathrm{~K}$ and $290 \mathrm{~K}\left(\lambda_{e x}=320 \mathrm{~nm}\right)$; b) Non-normalized solid-state emission spectra of $\mathbf{C}$ at $77 \mathrm{~K}$ at different excitation wavelengths; c) Normalized solid-state emission spectra of $\mathbf{D}_{\mathbf{P d}}$ at different temperatures between $430 \mathrm{~K}$ and $77 \mathrm{~K}$ upon excitation at $350 \mathrm{~nm}$ (full width at half maximum: $3040 \mathrm{~cm}^{-1}(80 \mathrm{~K}) ; 5580 \mathrm{~cm}^{-1}(430$ $\mathrm{K})$ ); the asterisk represents an instrumental artifact; Insert: plot of emission decay lifetime against temperature (80 K to $400 \mathrm{~K}$ ); red line represents the fit according to the TADF equation; d) Normalized solid-state emission spectra of $\mathbf{D}_{\mathbf{P t}}$ at different temperatures between $400 \mathrm{~K}$ and $77 \mathrm{~K}$ upon excitation at $350 \mathrm{~nm}$ (full width at half maximum: $2720 \mathrm{~cm}^{-1}(80 \mathrm{~K}) ; 4140 \mathrm{~cm}^{-1}(400$ $\mathrm{K})$ ); Insert: plot of emission decay lifetime against temperature ( $80 \mathrm{~K}$ to $500 \mathrm{~K}$ ); red line represents the fit according to the TADF equation.

from ca. $0.5 \mu$ s at $500 \mathrm{~K}$ to $c a .7 .9 \mu$ s at $80 \mathrm{~K}$ for $\mathbf{D}_{\mathbf{P t}}$ (Figure 4c,d, inset).

The emission behavior of $\mathbf{D}_{\mathbf{P d}}$ resembles those typically described for $\mathrm{Cu}(\mathrm{I})$ TADF derivatives. ${ }^{2}$ Fits of the decay lifetime measured for $\mathbf{D}_{\mathbf{P d}}$ were thus performed accordingly with Equation (1) derived from the TADF model. ${ }^{6}$ Values of $\Delta \mathrm{E}\left(\mathrm{S}_{1}-\mathrm{T}_{1}\right)$ $=1290 \mathrm{~cm}^{-1}, \tau\left(\mathrm{S}_{1}\right)=18.6 \mathrm{~ns}$ and $\tau\left(\mathrm{T}_{1}\right)=218 \mu$ s were extracted. They are comparable to those obtained for the precursor $\mathbf{A}$ $\left(\Delta \mathrm{E}\left(\mathrm{S}_{1}-\mathrm{T}_{1}\right)=1560 \mathrm{~cm}^{-1}, \tau\left(\mathrm{S}_{1}\right)=9.9 \mathrm{~ns} \text { and } \tau\left(\mathrm{T}_{1}\right)=185 \mu \mathrm{s}\right)^{4}$ and support $a$ priori a TADF mechanism. On the other hand, attempts to fit the decay lifetime for $\mathbf{D}_{\mathbf{P t}}$ to Equation 1 are less than satisfactory given the lack of data points at the high temperature regime. Nevertheless, a rough estimate of a $\Delta \mathrm{E}\left(\mathrm{S}_{1}-\right.$ $\mathrm{T}_{1}$ ) of $2980 \mathrm{~cm}^{-1}$ and a $\tau\left(\mathrm{T}_{1}\right)$ of $7.4 \mu \mathrm{s}$ is obtained by fitting the data to the TADF equation. ${ }^{11}$ The relatively large $\Delta \mathrm{E}\left(\mathrm{S}_{1}{ }^{-}\right.$ $\mathrm{T}_{1}$ ) estimated for $\mathbf{D}_{\mathbf{P t}}$ is still within the thermal energy barrier $\left(0.4 \mathrm{eV}\right.$ or $\left.3230 \mathrm{~cm}^{-1}\right)$ possible for reverse intersystem crossing (RISC). ${ }^{12}$ The shorter $\tau\left(\mathrm{T}_{1}\right)$ than those observed in the $\mathrm{Cu}(\mathrm{I})$ and $\mathbf{D}_{\mathbf{P d}}$ TADF systems is not unreasonable given the larger spin-orbit coupling constant for Pt. ${ }^{2 \mathrm{C}}$ Nevertheless, it is difficult to confirm the TADF nature for $\mathbf{D}_{\mathbf{P t}}$ with certainty as one cannot exclude the possibility of the competition between ISC to give phosphorescence and RISC to give TADF in $\mathbf{D}_{\mathbf{P}}$, i.e. platinum can provide significant spin-orbit coupling, resulting in efficient phosphorescence path in addition to the TADF path. ${ }^{13}$ Therefore, considering that $\mathbf{D}_{\mathbf{M}}$ derivatives are isostructural, the differences observed along the series clearly suggest a strong impact of the nature of the central $\mathrm{M}$ atom in 
their photophysical properties. Taking into account the large size of the molecules (417 atoms, 4417 basis functions) and

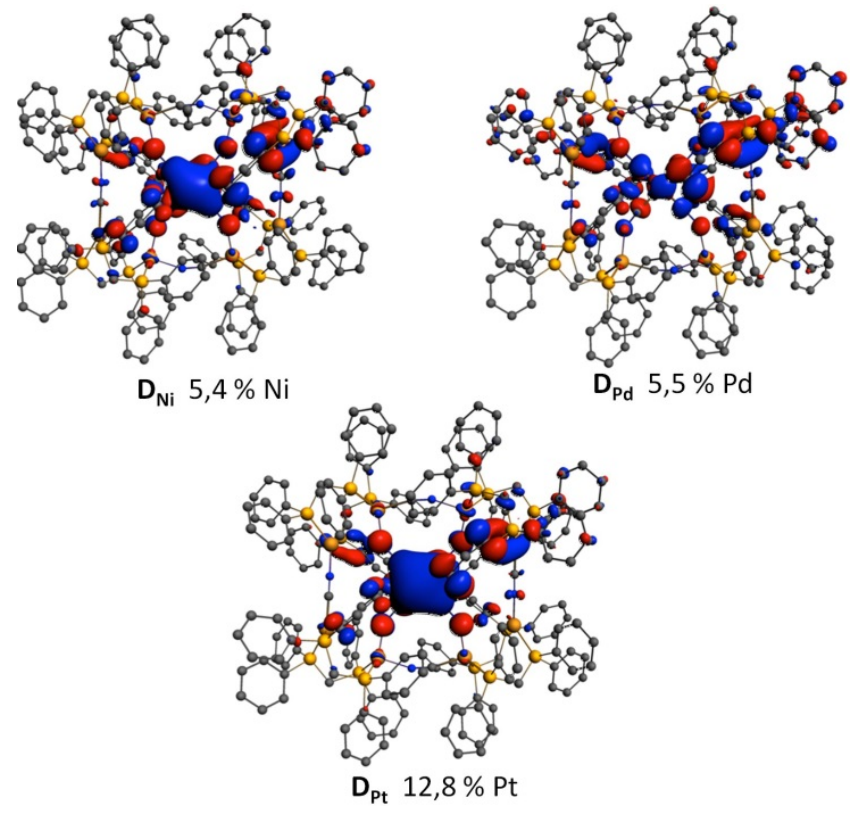

Figure 5. Isocontour plots $\left( \pm 0.02\left(\text { e.bohr }{ }^{-1}\right)^{1 / 2}\right)$ of the lowest unoccupied molecular orbitals (LUMO) of $\mathbf{D}_{\mathbf{M}}$ with the associated Mulliken atomic character for $\mathrm{M}$.

the influence of the solid state packing on the geometry, it was not possible to perform full DFT geometry optimization of the excited states to get deep insights about the electronic causes of these different photophysical properties. Nevertheless, the study of the molecular orbitals of the ground state and the nature of the first vertical singlet and triplet excited states of $\mathbf{D}_{\mathbf{M}}$ are significantly instructive. ${ }^{6}$ It reveals that in all cases the vertical excitation to $S_{1}$ is described by a combination of electronic transitions from the highest occupied orbitals to the lower-lying unoccupied orbitals. They include the LUMO at different scale depending on the central metal atom $(7.5 \%$ of the transitions for $\mathbf{D}_{\mathrm{Ni}} ; 43.7 \%$ for $\mathbf{D}_{\mathbf{P d}} ; 59.9 \%$ for $\left.\mathbf{D}_{\mathbf{P t}}\right){ }^{14}$ Moreover, these LUMOs are partly localized on the central metal atom at different extent regarding the nature of $\mathrm{M}$ : less than $6 \%$ of $\mathbf{M}$ atomic character for $\mathbf{D}_{\mathbf{N i}}$ and $\mathbf{D}_{\mathbf{P d}}$, while it reaches up to $12.8 \%$ for $\mathbf{D}_{\mathbf{P t}}$ (Figure 5). Consequently, the implication of the electronic density of the central metal atom in the overall electronic transition upon the excitation process is less than $1 \%$ for $\mathbf{D}_{\mathrm{Ni}}$, is $2 \%$ for $\mathbf{D}_{\mathbf{P d}}$ but reaches up to $8 \%$ for $\mathbf{D}_{\mathbf{P t}}$. This is nevertheless sufficient to imply enhancement of the spin-orbit coupling components both in the non-radiative and radiative processes involving $S_{1}$, with a magnitude order of $\mathrm{Ni}$ $<\mathrm{Pd}<<$ Pt. This may lead to the stronger competition between efficient ISC and efficient RISC that give rise to a competition between spontaneous phosphorescence and TADF along this series in agreement with the measured photophysical properties. Therefore, these observations demonstrate the crucial and somehow unanticipated impact of the nature of the central metal atom (and more specifically of its spin-orbit coupling value) on the luminescence properties of the entire $\mathbf{D}_{\mathbf{M}}$ assemblies.

\section{CONCLUSIONS}

The $\mathrm{Cu}(\mathrm{I})$ derivative $\mathbf{A}$ has been revealed to be a versatile preorganized precursor that provides a straightforward and rational access to a variety of luminescent polymetallic assemblies thank to its remarkable conformational flexibility. The origin and the diversity of both the supramolecular architectures obtained as well as the photophysical behaviour observed (with luminescence spectra spread across a large part of the visible spectra) highlight the unexplored potential of the use of such adaptive TADF $\mathrm{Cu}(\mathrm{I})$ molecular precursors in the fields of CDS toward new luminescent materials. Our current investigations intensively extend this synthetic route to other systems together with an in-depth understanding of their photophysical properties.

\section{ASSOCIATED CONTENT}

Supporting Information.

The Supporting Information is available free of charge on the ACS Publications website at DOI : $\mathrm{xxx} / \mathrm{xxx}$

Synthesis and characterization, X-ray crystallography, photophysical and computational studies (PDF)

Temperature dependent X-ray crystallography date for $\mathbf{C}$ (CCDC 184431 (100K), 184432 (175K) and 184434 (250K); CIF), $\mathbf{D}_{\mathrm{Ni}}$ (CCDC 184436 (150K); CIF), $\mathbf{D}_{\mathbf{P d}}$ (CCDC 184442 (100K), 184433 (150K), 184443 (200K) and 184441 (250K); CIF) and $\mathbf{D}_{\mathbf{P t}}$ (CCDC 184437 (100K), 184339 (150K), 184438 (200K) and 184440 (250K); CIF)

\section{AUTHOR INFORMATION}

\section{Corresponding Author \\ *mahdi.844@hotmail.fr \\ * karine.costuas@univ-rennes1.fr \\ *vwyam@hku.hk \\ * christophe.lescop@insa.rennes.fr}

\section{Notes}

The authors declare no competing financial interests.

\section{ACKNOWLEDGMENT}

This work was supported by the ANR (P-OPTOELECTRMOLMAT), the French Research Ministry and the CNRS. C. L. thanks the Alexander von Humboldt Foundation for a fellowship for experienced researcher. Computations were performed using HPC resources from GENCI-CINES/IDRIS (Grants-2016/80649 and A0020800649). V.W.-W.Y. acknowledges support from The University of Hong Kong and the URC Strategically Oriented Research Theme on Functional Materials for Molecular Electronics. This work has been supported by the University Grants Committee Areas of Excellence (AoE) Scheme (AoE/P-03/08) and a General Research Fund (GRF) grant from the Research Grants Council of the Hong Kong Special Administrative Region, P. R. China (HKU 17334216).

\section{REFERENCES}

(1) (a) Cook, T. R.; Stang, P. J. Chem. Rev. 2015, 115, 70017045. (b) Harris, K.; Fujita, D.; Fujita, M. Chem. Comm. 2013, 49, 6703-6712. (c) Wang, W.; Wang, Y-. X.; Yang, H.-B. Chem. Soc. Rev. 2016, 45, 2656-2693.

(2) (a) Czerwieniec, R.; Leitl, M. J.; Homeier, H.H.H.; Yersin, H. Coord. Chem. Rev. 2016, 325, 2-28. (b) Kobayashi, A.; Kato, M. Chemistry Letters 2017, 46(2), 154-162. (c) Hofbeck, T.; Monkowius, U.; Yersin, H. J. Am. Chem. Soc. 2015, 137, 399-404. (d) Bergmann, L.; Hedley, G. J.; Baumann, T.; Brase, S.; Samuel, D. W. Sci. Adv. 2016, 2, e1500889. 
(3) (a) Yam, V. W.-W.; Au, V. K.-M.; Leung, S. Y.-L. Chem. Rev. 2015, 115, 7589-7728. (b) Wong, K. M.-C.; Chan, M.-Y.; Yam, V. W.-W. Adv. Mater. 2014, 26, 5558-5568. (c) Tang, K. M.-C.; Chan, A. K.-W.; Chan, M.-Y.; Yam, V. W.-W. Top Curr Chem, 2016, 374, 1-43.

(4) El Sayed Moussa, M.; Evariste, S.; Wong, H.-L.; Le Bras, L.; Roiland, C.; Le Polles, L.; Le Guennic, B.; Costuas, K.; Yam, V. W.-W.; Lescop, C. Chem. Comm. 2016, 52, 11370-11373.

(5) (a) Lescop, C. Acc. Chem. Res., 2017, 50, 885-894. (b) El Sayed Moussa, M.; Evariste, S.; Krämer, B.; Réau, R.; Scheer, M.; Lescop, C. Angew. Chem. Int. Ed., 2018, 3, 795-799.

(6) For experimental details, spectroscopic, X-ray diffraction data and computational studies views see SI.

(7) Equal relative occupancies for $\mathrm{C}$ and $\mathrm{N}$ atoms have been modelled at the atomic position determined for the cyano ligands connecting two $\mathrm{Cu}(\mathrm{I})$ metal centers. For the $\mathrm{M}(\mathrm{CN})_{4}$ fragments, $\mathrm{C}$ atoms have been assigned to the atoms connected to the M(II) metal centres, see : Schneider, L.; Sivchik, V.; Chung, K-Y.; Chen, Y-T.; Karttunen, A.J.; Chou, P-T.; Koshevoy, I.O. Inorg. Chem. 2017, 56, 4459-4467.

(8) Upon temperature variation, no marked alteration of the metric parameters of the ${ }^{\prime} \mathrm{Cu}_{8} \mathrm{M}(\mathrm{CN})_{8}$ ' inorganic core is observed (Table S6); the volume contractions of the unit cells mostly affect the relative molecular arrangement of the $\mathrm{PF}_{6}{ }^{-}$counter-anions, the included solvent molecules and the peripheral dppm phenyl rings.

(9) Li, D.; Che, C.-M.; Wong, W.-T.; Shieh, S.-J.; Peng, S.-M. J. Chem. Soc. Dalton Trans., 1993, 653-654.

(10) (a) Lim, M. J.; Murray, C. A.; Tronic, T. A.; deKrafft, K. E.; Ley, A. N.; deButts, J. C.; Pike, R. D.; Lu, H.; Patterson, H. H. Inorg. Chem. 2008, 47, 6931-6947; (b) Lin, Y.-Y.; Lai, S.-W.; Che, C.-M.; Fu, W.-F.; Zhou, Z.-Y.; Zhu, N. Inorg. Chem. 2005, 44, 1511-1524; (c) Li, D.; Che, C.-M.; Kwong, H.-L.; Yam, V. W.-W. J. Chem. Soc. Dalton Trans. 1992, 3325-3329; d) Yam, V. W.-W. Acc. Chem. Res. 2002, 35, 555-563.

(11) Using equation (1) for fitting the decay lifetime of $\mathbf{D}_{\mathbf{P t}}$ afforded values of $\Delta \mathrm{E}\left(\mathrm{S}_{1}-\mathrm{T}_{1}\right)=2980 \mathrm{~cm}^{-1}, \tau\left(\mathrm{S}_{1}\right)=0.09 \mathrm{~ns}$ and $\tau\left(\mathrm{T}_{1}\right)=$ $7.4 \mu \mathrm{s}$.

(12) Endo, A.; Ogasawara, M.; Takahashi, A.; Yokoyama, D.; Kato, Y.; Adachi, C. Adv. Mater. 2009, 21, 4802-4806.

(13) Schinabeck, A.; Leitl, M.J.; Yersin, H. J. Phys. Chem. Lett. 2018, 9, 2848-2856.

(14) The nature of the electronic excitation S1 combines transitions that mainly involves electronic density around $\mathrm{Cu}$ atoms and phosphines (see Figure S34).

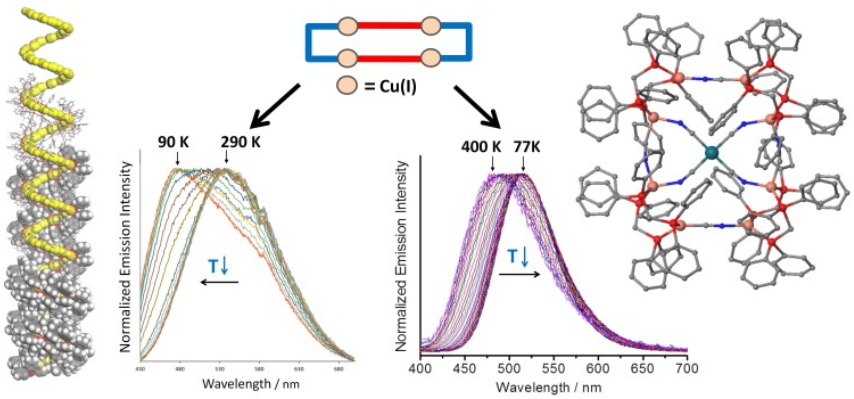

